\title{
The Low Co-occurrence of Nominalization and Hedging in Scientific Papers Written by Chinese EFL Learners
}

\author{
Xiao Liu \\ College of Foreign Languages \\ Nanjing University of Aeronautics and Astronautics, \\ Nanjing, China \\ Email: maggieliuxiao@nuaa.edu.cn
}

Received: $12 / 24 / 2020$

Accepted: 3/2/2021

Published: $3 / 24 / 2021$

\section{Abstract}

This article hypothesizes that one of the reasons for Chinese EFL learners' rigid use of nominalization and insufficient use of hedging in academic writing can be attributed to the unclear understanding of the relationship between these two expressions. The aim of the research is to first prove and then explain the possible co-occurrence of nominalization and hedging in scientific papers, with the intention of deepening Chinese EFL learners' understanding of the reasons for their possible co-occurrence. After a corpus-assisted statistical analysis of sixty abstracts selected from leading scientific journals written by native English speakers, it's been found that there is indeed a tendency for nominalization and hedge to co-occur both at the textual-level and clause-level. Besides, a tentative analysis is conducted to explain the pattern of their co-occurrence. It has been observed that the number of nominalized expressions in clauses is inversely correlated with the probability degree of hedging, and the position of nominalization in the clause (theme or rheme) influences the generalization level of hedging. The research results could shed light on the pedagogic approach in improving Chinese EFL learners' academic writing by making evident that the elusive Grammatical Metaphor competence could be enhanced by deepening the understanding of the inter-relationship between seemingly different in-congruent expressions like nominalization and hedges.

Keywords: Chinese EFL learners, co-occurrence, hedge, nominalization, Systemic Functional Linguistics

Cite as: Liu, X. (2021). The Low Co-occurrence of Nominalization and Hedging in Scientific Papers Written by Chinese EFL Learners. Arab World English Journal, 12 (1) 401-420.

DOI: https://dx.doi.org/10.24093/awej/vol12no1.27 


\section{Introduction}

Nominalization refers to the process in which any element or group of elements in sentences are made to function as nominal groups in the clauses, which can strengthen the ideational function of language and enhance the objectivity and authority of the argumentation ( Fan, 1999; Halliday, 1994). The proper use of nominalization can condense information and improve persuasiveness, which is also why nominalization is recognized as a key feature in academic discourse (Biber, 2006; Charles, 2003; Hyland, 2004a, 2004b; Ryshina-Pankova, 2015). However, prior empirical researches in English for Academic Purpose(EAP) studies in China have shown that the deployment of nominalization in academic writings of Chinese postgraduate EFL learners tends to be either insufficient or redundant(Tan, 2011), which has become one of the major obstacles in improving Chinese EFL students' academic English writing skills.

According to Systemic Functional Linguistics(SFL), nominalization is defined as the single most powerful resource for creating grammatical metaphors (GM) (Halliday \& Martin, 1993), ideational GMs in particular. Guided by the harmonious relationship between the three metafunctions (ideational, interpersonal, textual), the enhanced ideational function needs to be balanced with the interpersonal function, of which hedging plays an essential role. Therefore, based on the theoretical complementarity between nominalization and hedging within SFL framework, the current research hypothesizes that there is a pattern of co-occurrence between nominalization (the representative of ideational GM) and hedging (the representative of interpersonal GM) in academic discourse, and the author intends to prove their possible cooccurrence at clausal and textual level with statistical analysis and corpus search results. At the textual level, 60 abstracts of articles written by native English speakers from leading international academic journals of science and engineering since 2014 were collected and analyzed in SPSS. It was verified that there is a positive correlation between the number of sentences containing nominalization and that containing hedging through linear regression analysis. At the clausal level, BNC corpus-assisted analysis found that the frequency of the cooccurrence between nominalization and hedging in scientific papers is higher than in nonacademic genres. Finally, within the framework of systemic functional grammar, a tentative reason analysis for the co-occurrence between nominalization and hedging was conducted along with the illustration of typical examples. Through the statistical analysis of the interactions between the deployments of two major GMs in academic discourse, the present study aims to provide pedagogical implications to teaching the appropriate usage of nominalization and hedging in academic discourse to Chinese EFL learners integrating SFL theory with EAP teaching.

Enlightened by the theoretical complementarity between nominalization and hedging, and the pragmatic need for effective academic communication, this study attempts to answer the following questions: (1) Is there a positive correlation between nominalization and the use of hedging in the abstracts of scientific papers? (2) What is the normal frequency of the cooccurrence between nominalization and hedging in the academic genre within BNC corpus ? (3) How to explain the co-occurrence between nominalization and hedging within the systemic functional linguistic framework? 


\section{Literature Review}

The appropriate use of nominalization in academic discourse, especially in the composition of abstracts, is crucial to advanced EFL learners. However, it has been proven that the cultivation of grammatical metaphorical competence, which includes the usage of nominalization, poses challenges to EFL learners (Liadret, 2013); specifically, the application of derivative nouns and nominal phrases or clauses, especially the number of transformations of transitive messages in rheme to nominal phrases in theme through nominalization of the academic writing of Chinese EFL learners is lower than that of native speakers (Li \& Guo, 2020). Besides, there are frequent ungrammatical misuses in nominalization, including both "interlanguage" and "inner-language" English nominal errors (Luo, 2006), which may cause confusion and ambiguity in writing.

\section{The Inadequate Integration of GM with EAP Teaching Practice in China}

According to the previous studies, reasons for Chinese EFL students' inefficacy in using nominalization resides in the lack of knowledge about the contrastive language characteristics between English and Chinese, as well as the inaccurate understanding of stylistic features of scientific writing (Tan, 2011). It can be observed that the reasons provided above are in lack of theoretical support and can hardly prove of significant help to English teaching practice in China. Scholars from home and abroad who have taken an interest in studying the EFL teaching status in China have also demonstrated that studies integrating SFL theory with English instruction are much fewer than the descriptive studies about SFL theories (Hu \& Fang, 1997; Huang, 2002; Yang, 2008, 2011). Furthermore, Lam (2002) has pointed out that the teaching of GM as a resource for successful writing was completely absent from Chinese universities' English curriculum. This article concurs with Lam's claim and contends that even the EAP lessons of Chinese higher education, which are designed to improve postgraduates' academic writing skills, have not fully deployed GM as a resource to assist students in achieving academically valued writings. Moreover, we believe that one of the neglected reasons for the inappropriate nominalization deployment is that the meta-functions of nominalization as a GM, as well as the ideational and interpersonal meanings of combing different GMs are not disclosed to students in EAP teaching practice. The lack of meta-functional knowledge of nominalization and GMs prevents students from comprehending the functional meaning of formal grammars, resulting in misuses.

In recent years, a number of Chinese scholars have carried out preliminary explorations about teaching GM as a key resource for composing academic discourse in EAP classes for advanced EFL learners(Sun \& Shao 2011; Zhang, 2019; Zhong \& Chen, 2015), yet most of the studies are limited to the categorization of students' mistakes concerning one kind of GM usage, with the utmost attention paid to one representative type of nominalization - the transformation from verbs or adjectives to nouns (Zhang, 2016). Very few efforts have been made to systematically analyze the essential factors influencing the language choices made by the students in using various GMs, including nominalization and other forms of GMs. In other words, students' metaphorical competence is not investigated comprehensively, the focus on using nominalization is not studied together with other grammatical metaphors. While according to SFL, language is viewed as a semiotic system, which considers the hierarchical organization of language system as important as the lexicon-grammatical expressions themselves (Halliday \& Mathiessen, 2004). That means, in terms of metaphorical competence, not only the functioning mechanism of various GMs needs to be learned, but also the relationship between various GMs. 


\section{A Review of Research on Nominalization and Hedging}

Research on nominalization began in the 1980s with the initiation of the analysis of syntactic structure from the perspective of GM (Halliday \& Hasan, 1985). According to Halliday, metaphor is formed when the congruence is broken in language. When this rule is broken, a metaphorical expression takes its form. In this way, nominalization has become a potent source for GM since nominal phrases are employed to refer to process itself rather than the participants of the process. Ever since Halliday brought up the concept of GM in the 80 s, there has been a growing tendency among Chinese scholars to investigate GM from different perspectives, including its nature, types, functions, ways of realization and its mechanism ( $\mathrm{Hu}, 1997$; Zhu \& Yan, 2000). In the 21st century, due to the increased inter-disciplinary cooperation between linguistics, sociology, anthropology and psychology, the research on GM, especially nominalization, has gained more momentum, and scholars began to draw on theories from logical semantics and pragmatics to explain the formation and function of it (Martin, 1992; Lemke, 1998; Zhu, 1994). From the perspective of semantics, Zhu (2006) pointed out that nominalization provides a new cognitive perspective through re-categorization, which plays an essential role in condensing information in texts.

For example,

[1a] The driver drove the bus too fast down the hill, so the brakes failed.

[1b] The driver's over-rapid downhill driving of the bus caused brake failure. (Zhu, 2006:84)

$1 \mathrm{~b}$ is the in-congruent form of $1 \mathrm{a}$, since both the three participants and the contextual meaning are turned into attributive components in $1 \mathrm{~b}$, the logic meaning is represented as the process, and the process is turned into participant through nominalization. The example given by Zhu (2006) clearly demonstrated the potential possibility existed in the tension between the lexico-grammatical level and semantic level. However, when it's relatively easier to realize ideational functions through experience re-configuration and re-processing, as well as the substantialization of attributes, things become trickier when emotion and attitude get involved. The re-configuration achieved mainly through nominalization could weaken or even erase the interpersonal function of the language expressions. In order to compensate for the weakened interpersonal function, modality and evaluation are deployed, of which the usage of hedging accounts for a large portion (Tang, 2014). As an essential form of modal structure, hedging focuses on the realization of interpersonal function. The proper use of hedging can realize the transmission of interpersonal meaning through the refinement of the range and value of facts (Lakoff, 1975; Cai \& Dai, 2002). As opposed to nominalization, the appropriate deployment of hedging can better reflect the interpersonal function of language without detracting the technicality of the academic discourse, and their use is part of pragmatic competence (Skelton, 1988).

The need to enhance communicative effectiveness of academic discourse by highlighting interpersonal function through hedging against the usage of nominalization is even more urgent when it comes to scientific papers. In scientific papers, writers usually need to make a critical review of the relevant prior literature to be able to establish their own research niche (Swales, 1990). While using nominalization allows the authors to generalize the opinions given by the previous studies with technicality and lexical density, it also tends to reduce negotiability of the text (Hyland, 1998), leaving readers no room for questioning but passively accept the 
unassailable argument of the authors. However, it's very likely for the seemingly authoritative argument fail to realize its effective communicative purpose, the reason of which is associated with the face-saving theory of politeness proposed by Brown and Levinson (1978). Politeness strategies help to negotiate and achieve the most favorable outcomes in conversations. Academic writing, despite being highly professional and technical, is still a way of communication, thus the same politeness strategies can also apply to academic discourse. That is, in order to make our criticism of the deficiencies in the previous work more acceptable, the affirmation of the previous efforts and the softening of your wordings in criticisms are required. One of the major ways in realizing that "softening" is through the appropriate use of hedging(Ying \& Zhou, 2009).

\section{The Theoretical Complementarity between Nominalization and Hedging}

It has been mentioned above that although the use of nominalization enhances objectivity, authority and information density, it reduces communication effectiveness at the same time (Zhou \& Liu, 2017). In other words, when nominalization is applied, the "ideational" function among the three meta-functions of language is amplified, and the "interpersonal" function is minimized. Based on the harmonious balance between the three meta-functions of language in SFL, it is logical to assume a possibility for expressions stressing different meta-functions to complement each other. One of the most common ways to enhance and compensate the weakened interpersonal function due to nominalization in academic discourse is by the adoption of proper hedging, since by making things less fuzzier, the negotiability of the sentences is usually increased (Lakoff, 1972). However, it needs to be clarified that the subjective interpersonal metaphors, which in a broader sense can be attributed to the group of hedges, are very rarely deployed in academic discourse, due to the fact that the accumulation of explicit subjective meanings foregrounded in a thesis is particularly detrimental to the construction of academically valued texts (Schleppegrell, 2005). The intricacy of using proper hedging increases the difficulty in cultivating the interpersonal metaphorical competence among EFL learners.

In the last two decades, research concerning authorial stance in academic discourse has laid more emphasis on the study of hedging (Hyland, 2005; Jiang, 2016). Different from providing necessary information or required "hard-evidence" to support arguments, which is usually realized through nominalization, hedging is deployed to avoid absoluteness in the meaningmaking process, thus facilitating the effective communication of academic ideas. Briefly, if nominalization highlights the ideational function by condensing information and sending the clear message, then hedging is conducive to packaging the messages in a pleasant appearance so that it's easier for readers to accept your arguments. Corpus-based research has demonstrated that hedging is frequently applied in academic discourse to express authors' opinions and interpretations of the experimental statistics (Flowerdew, 1997). The diachronic study of the use of hedging in scientific papers conducted by Jiang (2016) also revealed an increasing amount of hedge uses, which reflects that authors in academia are attaching more importance to constructing their stance in academic discourse. However, despite the demand for a higher percentage of hedging, Chinese postgraduate EFL learners tend to overuse only a particular type of hedging, such as attitudinal type and the style-of-speaking kind, which is in lack of diversity (Xu, 2011). Besides, although relevant studies on hedging have started to pay attention to its pragmatic functions(Wang \& Sun, 2018; Jiang, 2013), the research on the context of using hedging, and why in certain sentences the possibility and frequency of hedge-using is increased have not been thoroughly investigated. 
Through the above discussion of prior works on nominalization and hedging in academic discourse, it is not difficult to observe that the misuse of nominalization and that of hedging in Chinese EFL learners' academic writings share similar features, namely, the imbalanced deployment of various types, and the repeated overuse of certain lexicon-grammatical expressions, exposing students' fragmented comprehension of the systemic functions of grammar, which can once again be attributed to the lack of integration of GM knowledge, or SFL theory in general, in EFL teaching practice. In addition, the sudden shift from grammar-centered pedagogy in China's English education to Communicative Language Teaching also contributed to students' inadequacy in appropriately using in-congruent forms (Campbell \& Yong, 1993).

Apart from the similar ground shared by nominalization and hedging in the common errors regarding the deployment of GM among Chinese postgraduates, both the harmonious relationship between three language meta-functions stipulated by SFL(Halliday \& Matthiessen, 2013) and the requirement for effective communication $(\mathrm{Xu}, 2006)$ call for the investigation on the relationship between the two in academic discourses. SFL has made clear that nominalization and hedging are theoretically complementary in terms of linguistic meta-functions. Specifically, hedging is defined as a strategy or technique to soften the magnitude of the language and enhance acceptability of readers(Nikula, 1997), and hedging can also function as face-saving strategy as well as making things less fuzzier (Lakoff, 1972). Up to now, there have been correspondent corpus-based quantitative studies dedicated to the usage of nominalization or hedging in scientific papers both in China and abroad (Chen \&Wen, 2020; Liardét \& Black, 2020; Park, 2019; Liu \& Chen, 2019; Yoon, 2018; Prasithrathsint, 2014), yet very few corpusbased statistical analyses have been conducted with respect to their possible co-occurrence in academic discourse.

\section{Methods}

\section{Corpus-based Methods}

The data for study were collected from sixty abstracts of scientific papers in leading academic journals, such as Journal of Applied Physics, Information \& Computation, Applied Surface Science, Physics in Medicine and Biology, were selected to form a mini-corpus. The disciplines mainly include material science, engineering design, computer science technology and automation. The number of sentences involving nominalization and those involve hedging in abstracts were counted and a linear regression analysis was conducted between the two groups of data in SPSS to see whether there is positive correlation between the two. Then the frequency of the co-occurrence between nominalization and hedging within academic writing and nonacademic writing was compared with the help of BNC. After that, the reasons for their cooccurrence were analyzed within the SFL framework along with typical examples retrieved from the corpus.

\section{Research Procedures}

The research could be divided into four main steps: firstly the author identified the typical nominal affixes including -ance, -ence, acy, -tion, -ment, -ness, -ity, etc. and used these nominal affixes to search for nominalization in the mini-corpus of abstracts. The representative nomial affixes as well as the nominalization could be found in the following Table one. After that, the author has manually filtered the searching results, excluding nouns referring to concrete objects, retaining only nominalization that are GMs. 
Arab World English Journal (AWEJ) Volume 12. Number 1. March 2021

The Low Co-occurrence of Nominalization and Hedging

Liu

Table 1. The number and percentage of nominalization in the mini-corpus

\begin{tabular}{|c|c|c|c|c|}
\hline $\begin{array}{l}\text { Nominal } \\
\text { Affixes }\end{array}$ & Meanings & Examples & No. & Percentage \\
\hline -ance,-ence & $\begin{array}{l}\text { Meaning "nature, } \\
\text { condition, behaviour, } \\
\text { process, total, degree" }\end{array}$ & $\begin{array}{l}\text { endurance, importance, } \\
\text { diligence, difference, } \\
\text { obedience }\end{array}$ & 41 & $14.69 \%$ \\
\hline -acy,-ency, & $\begin{array}{l}\text { Meaning "nature, state, } \\
\text { situation, behaviour, } \\
\text { process" }\end{array}$ & $\begin{array}{l}\text { frequency, } \\
\text { efficiency, }\end{array}$ & 11 & $3.94 \%$ \\
\hline -ity (bility) & $\begin{array}{l}\text { Meaning "action, } \\
\text { nature, state, degree" }\end{array}$ & possibility, feasibility & 67 & $24.01 \%$ \\
\hline $\begin{array}{l}\text {-ion,-sion,- } \\
\text { tion,-ation,- } \\
\text { ition }\end{array}$ & $\begin{array}{l}\text { Representing "process } \\
\text { of behaviour, result, } \\
\text { situation" }\end{array}$ & $\begin{array}{l}\text { action, solution, } \\
\text { conclusion, destruction, } \\
\text { expression, correction }\end{array}$ & 110 & 39. $42 \%$ \\
\hline- ment & $\begin{array}{l}\text { Meaning "behaviour, } \\
\text { state, process, means } \\
\text { and results" }\end{array}$ & $\begin{array}{l}\text { treatment, movement, } \\
\text { judgment, punishment, } \\
\text { argument }\end{array}$ & 35 & $12.54 \%$ \\
\hline -ness & $\begin{array}{l}\text { Meaning "nature, state, } \\
\text { degree" }\end{array}$ & $\begin{array}{l}\text { goodness, kindness, } \\
\text { tiredness, friendliness }\end{array}$ & 15 & $5.37 \%$ \\
\hline
\end{tabular}

The same searching method was employed in the identification of hedging in the collected abstracts. Different forms of hedging were retrieved according to the classification criteria of hedging at the vocabulary level given by Zhu \& Xia (2011): including modal auxiliary verbs, such as may, could, should, would, will, propose; modal adverbs and adjectives like possible (ly), probable (ly), often, frequent (ly); and some modal nouns, such as assumption, argument, claim. The filtered hedging can be seen in the following Table two. The searched hedges are further categorized according to the division of hedge types given by Prince et al. (1982), including the adjectives, adverbs and noun phrases, as well as the lexical verbs that meet the semantic and pragmatic functions of hedging, and the adjectives, adverbs and nouns are further divided into two types: approximates and diffusers. The other categorizations of hedges proposed by Hyland (1998) and Yang (2011) also follow the basic model established by Prince, including cognitive modal verbs, cognitive adjectives, nouns and adverbs, as well as cognitive verbs. 
Arab World English Journal (AWEJ) Volume 12. Number 1. March 2021

The Low Co-occurrence of Nominalization and Hedging

Liu

Table 2. The categorization of hedging found in the mini-corpus

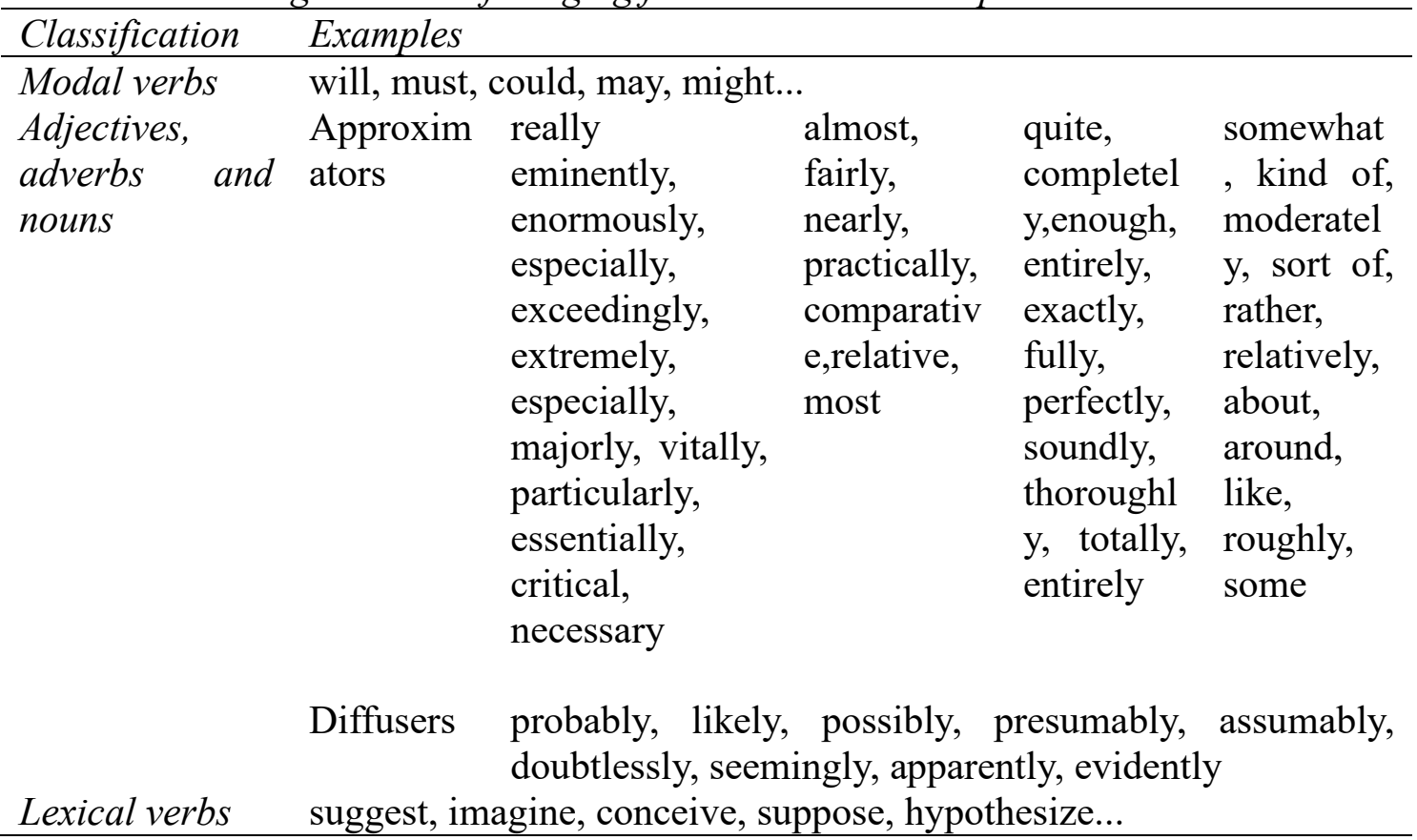

The number of sentences containing nominalization and the number of sentences containing hedging were calculated, and the original descriptive statistics for the 60 abstracts were presented in Table three.

Table 3. General descriptive statistics

\section{Descriptive statistics}

Average Standard

value deviation

Cases

\begin{tabular}{lccc}
\hline $\begin{array}{l}\text { Sentences with } \\
\text { nominalization }\end{array}$ & 2.83 & 1.758 & 60 \\
\hline Sentences with hedging & 1.35 & 1.102 & 60 \\
\hline
\end{tabular}

The linear regression analysis between the sentences with nominalization and those with hedging will be shown in the results section. And after the SPSS analysis of the statistics, sentences that contain both nominalization and hedging were retrieved from scientific and technical academic texts (ac:tech, engin) and non-academic scientific and technological texts (non_ac:tech_engin) of the BNC corpus, and the frequency of their co-occurrence was compared. The last research step is devoted to the tentative reason analysis of their co-occurrence within the framework of systemic functional grammar, paying special attention to interpersonal pragmatics, and typical example sentences will be analyzed centering on the concepts of negotiability and thematicity.

\section{The Correlation Analysis of Nominalization and Hedging in SPSS}

A total of 179 sentences using nominalization were identified in sixty English abstracts, for a total of 279 nominalization. The total number of selected abstract sentences was 441, and the sentences containing nominalization accounted for $40.5 \%$ of the total amount, which suggests that nominalization is frequently deployed in scientific papers. The total number of sentences 
with hedging is 81 , accounting for $18.3 \%$. The total amount was lower than the sentences with nominalization, indicating that there does not exist a one-on-one co-occurrence between the two, but this data does not rule out the possibility that their frequency of use at the textual level is positively correlated. The data were imported into SPSS.26 for correlation matrix analysis, a Ttest for the samples, and a linear regression analysis, the number of sentences with nominalization was set as the dependent variable, and the number of sentences with hedging as the predictor variable. The results were shown in the following tables.

Table. 4 Pearson correlation coefficient square matrix Correlation

\begin{tabular}{llrrr} 
& & \multicolumn{1}{c}{$\begin{array}{c}\text { Sentences with } \\
\text { nominalization }\end{array}$} & \multicolumn{2}{c}{$\begin{array}{c}\text { Sentences with } \\
\text { hedging }\end{array}$} \\
\hline Pearson correlation & $\begin{array}{l}\text { Sentences with } \\
\text { nominalization }\end{array}$ & 1.000 & .713 \\
\cline { 2 - 5 } & Sentences with hedging & .713 & 1.000 \\
\hline $\begin{array}{l}\text { Significance } \\
\text { tail) }\end{array}$ & (single & $\begin{array}{l}\text { Sentences with } \\
\text { nominalization }\end{array}$ &. & .000 \\
\cline { 2 - 4 } & \begin{tabular}{l} 
Sentences with hedging \\
\cline { 2 - 4 }
\end{tabular} & Sentences with hedging & .000 &. \\
\cline { 2 - 4 } & & 60 & 60 \\
\hline
\end{tabular}

Table. 4 reveals that the significance of Pearson correlation coefficients is $\operatorname{high}(\mathrm{P}<0.01)$, which indicates a significant positive correlation between the number of sentences with nominalization and the number of sentences with hedging.

Table.5 T test results of the regression model

\begin{tabular}{|c|c|c|c|c|c|c|}
\hline \multicolumn{7}{|c|}{ ANOVA } \\
\hline Model & & $\begin{array}{l}\text { Sum of } \\
\text { squares }\end{array}$ & $\begin{array}{l}\text { Degrees of } \\
\text { freedom }\end{array}$ & $\begin{array}{l}\text { Mean } \\
\text { square }\end{array}$ & $\mathrm{F}$ & Distinctiveness \\
\hline \multirow[t]{3}{*}{1} & Eeturn & 92.704 & 1 & 92.704 & 59.990 & $.000 \mathrm{~b}$ \\
\hline & Residual & 89.629 & 58 & 1.545 & & \\
\hline & Total & 182.333 & 59 & & & \\
\hline
\end{tabular}

a. Dependent variable: the number of sentences with nominalization

b. Predictor: (constant), the number of sentences with hedging

Table.6 Regression coefficient and its significance test result

\begin{tabular}{|c|c|c|c|c|c|c|}
\hline \multicolumn{7}{|c|}{ Coefficient } \\
\hline \multirow{2}{*}{\multicolumn{2}{|c|}{ Model }} & $\begin{array}{r}\mathrm{UN}-\mathrm{s} \\
\mathrm{co} \\
\end{array}$ & $\begin{array}{l}\text { dardized } \\
\text { cient }\end{array}$ & $\begin{array}{c}\text { Standardized } \\
\text { coefficient }\end{array}$ & \multirow{2}{*}{$\frac{\mathrm{t}}{5.08}$} & \multirow[b]{2}{*}{ Distinctiveness } \\
\hline & & B & $\begin{array}{l}\text { Standard } \\
\text { error }\end{array}$ & Beta & & \\
\hline \multirow[t]{2}{*}{1} & (Constant) & 1.298 & .255 & & $\begin{array}{r}5.08 \\
8\end{array}$ & .000 \\
\hline & $\begin{array}{l}\text { Sentences with } \\
\text { hedging }\end{array}$ & 1.137 & .147 & .713 & $\begin{array}{r}7.74 \\
5 \\
\end{array}$ & .000 \\
\hline
\end{tabular}

a. Dependent variable: the number of sentences with nominalization 
Model test results in the linear regression analysis of Table. 5 and Table. 6 show that the number of sentences with nominalization, which is the dependent variable-a in the above tables, has a significant effect on the predictor variable $b$ (the number of sentences with hedging) (Distinctiveness $<0.01$ ). Correlation analysis in Table.4 shows that there is a significant positive correlation between the two variables ( $a$ and $b$ ). Through the statistical analysis, the results reflect that the number of sentences using hedging in abstracts increases with the increase of sentences with nominalization. In other words, there is a positive correlation between the usage of nominalization and hedging in abstracts of scientific papers, and it's reasonable to hypothesize a pattern for their co-occurrence in academic writing.

\section{The Comparison of Co-occurrence Frequency Using BNC Corpus}

The correlation analysis in the section above confirmed the co-occurrence between nominalization and hedging at the textual level; that is, the number of nominalization and the number of hedging employed in abstracts are positively related. The second research question of this study is to prove that their co-occurrence also exists at the sentence level, or clausal level. The BNC corpus was used to verify their co-occurrence at the clausal level. Specifically, the typical suffixes of nominalization and hedging were used to construct the search formula: "?? +[zation, sation, ition]" (for nominalization), and "*ly_AV0" stands for hedging, the frequency of their co-occurrence are searched both from the scientific writing corpus (ac:tech_engin) and nonacademic text (non_ac:tech_engin). The corpus search results were listed in the following two tables.

Table.7 Comparison of search results in the collocation of nominalization and hedging in BNC corpora

\begin{tabular}{llcl}
\hline Genre & \multicolumn{2}{c}{ Nominalization + hedging } \\
& Hits & Texts & Frequency \\
\hline ac: tech_engin & 772 & 22 & $0.1120 \%$ \\
non_ac: tech_engin & 503 & 118 & $0.0422 \%$ \\
\hline
\end{tabular}

The first 100 sample sentences were selected randomly in the academic writing corpus to check whether the adverbs ending with "-ly" in the corpus search indeed belong to the domain of hedging. After the manual screening, we found that there were 27 sentences containing adverbs ending in "-ly" that were not hedging, including sentences using modifying adverbs such as "inversely, secondly, analogously, consequently, automatically and experimentally". However, although the 27 sentences with nominalization lack adverbial hedging ending with "-ly", 16 sentences contained other forms of hedging, such as adverbs: "sometimes, often" in Eg. 1 and 2; modal auxiliary verbs: "would, may, must, could" in Eg.3, 4, 5 and 6; adjectives: "many" in Example seven; nouns: "probability" in Eg. 8; verbs: "assume, propose" in Example nine and ten; and hedging in the form of an adverbial phrase: "to a certain extent" in Eg. 11.

Eg.1: The character '? ', or 'wild card' character (mentioned previously in section 3.4.1) is sometimes given as output from the pattern recognizer for letter positions where the recognition could not match with any known character encoding.

Eg.2: The coefficient of expansion shows a pronounced peak, similar to that observed experimentally and often confused with a first-order transition. 
Eg.3: It was noted at that time that there was low-level information technology utilization in the departments; consequently, the cost of implementation would be a significant factor when considering the design of either system.

Eg.4: Consequently, recognition systems may not show the speed, adaptability and flexibility of the human system until they do.

Eg.5: The size and position of this bolt and hole are as yet undeclared; the only specification is that they must fit together when drawn, so a hole of the wrong size or in the wrong position will be automatically reported.

Eg.6: For example, domains that are closely related may have a large number of collocations in common, such that the recognition of one could be facilitated by a dictionary taken from the other.

Eg.7: Many products contain mechanisms that are interfaced to electronics and with the advances in miniaturization of these products, it is only the special-purpose machines which possess the skills to manufacture and assemble them.

Eg.8: Transition probabilities $\mathrm{p}(1)$ top(4) in Table 6.2 are calculated by counting the number of times the business executive stayed in city a and subsequently (i) stayed the next day in the city a, (ii) moved to city b, (iii) moved to city c, (iv) moved to city d.

Eg.9: So far it has been assumed that levels of processing within the system operate serially, from the pattern recognition to the lexical lookup, then onto the syntactic and semantic analysis.

Eg. 10: In its original form waveform detection was based on the modulating effect on the phase current of the motional voltage (which in turn is a function of rotor position), but more recently a scheme using the variation of phase inductance with rotor Position has been proposed.

Eg.11: To a certain extent, this process may be seen as part of the more established technology known as OCR (Optical Character Recognition), but OCR has traditionally been associated exclusively with machine printed text rather than handwriting.

(All the sample example sentences are retrieved from BNC corpus)

Therefore, the co-occurrence frequency of the nominalization and hedging in academic discourse excluding non-hedging is $0.997 \%$, which is still much higher than the $0.0422 \%$ frequency rate in non-academic texts. The corpus search thus also confirmed a high frequency of co-occurrence between nominalization and hedging at the clausal level.

\section{A Tentative Reason Analysis of the Co-occurrence between Nominalization and Hedging in Scientific Papers}

Combined with the example sentences with nominalization and hedging of English academic abstracts, the reasons for their co-occurrence are analyzed from negotiability and thematicity within the framework of Systemic Functional Grammar(SFG). From the perspective of functional analysis, negotiability is reduced when the independent clause is downgraded to a dependent one, and the negotiability of non-finite dependent clauses is even further reduced. For example, by changing the sentence "They arrived after finishing the security check" into "Their arrival after finishing the security check", the second non-finite dependent clause leaves less room for negotiation compared with the first independent clause, because the nominalization of the process " arrived" has made the "arriving process" an assumed fact, which reduces the negotiability of the clause. As can be seen from the example, nominalization plays a crucial role in the process of reducing the negotiability of clauses. Another concept directly related to negotiability is "distance". A decrease in the negotiability of clauses means that the distance 
between the author and the reader enlarges. The professionalism and sense of distance of academic writing are mainly achieved through nominalization. Compound noun phrases formed through nominalization can meet the need to convey high-density information in scientific and technological texts, but to a certain extent a large number of nominalization has become a discourse marker of power and status (Halliday\&Matthiessen, 2013). It is therefore necessary to adopt the modal structure of interpersonal functions to minimize the side-effect of nominalization.

\section{The Relationship between Value of Hedging and the Number of Nominalizations}

As one of the main realizations of modality, the use of hedging in complex sentences can compensate for the negotiability reduction caused by nominalization. Not only does hedging refine the process by the degree of possibility and the scope of influence, they also increase the semantic potential and modal meaning. The primary forms of hedging are adverbs or adverbial phrases, and hedging that refines the sentence from degree to a large extent overlap with modal adjunct, which is one of the three main types of adjuncts according to the adjunct categorization in SFL(circumstantial adjuncts, modal adjuncts and conjunctive adjuncts), the proportion of sentences containing hedging with varying degrees is listed in the following Table. 8; and the reason analysis for the co-occurrence between nominalization and hedging of degree will be discussed in the following part of this section. Another category of hedging refers to those that limit the scope of certain process, which corresponds to the conjunctive adjuncts in SFL. The reason analysis for the co-occurrence between this category of hedging and nominalization will be investigated in the next section.

Table.8 The classification of hedging expressing degree (modal adjuncts) and their percentage in abstracts

\begin{tabular}{llllll}
\hline Hedging & Possibility & Intensity & Usuality & Obligation & Inclination \\
\hline Number & 31 & 32 & 7 & 4 & 8 \\
Proportion & $37.8 \%$ & $39 \%$ & $8.5 \%$ & $4.9 \%$ & $9.8 \%$ \\
\hline
\end{tabular}

The above Table eight classified a total of 82 sentences containing hedging filtered in the abstract of scientific papers in English. It can be seen that Possibility and Intensity are the most frequent forms of hedging in scientific papers. It is also in consistence with the internal logic of scientific research, since the determination of research questions in the beginning part of the paper usually requires a hypothesis of possibility and the emphasis of topic significance. Besides, the simulation experiments are carried out to verify the effectiveness of a proposed solution, which also requires a higher percentage of intensity hedging.

The following analysis takes the possibility hedge as an example, and further divides the example sentences into four situations according to the subjectivity and explicitness of the expression. The terms subjectivity and explicitness originate from Halliday's categorized analysis modal adjuncts. According to Halliday and Matthiessen(2013), the value of modal judgment can be divided into high, median and low, and its orientation consists of subjectivity and objectivity, explicitness and implicitness, which could compose four choices in modalization and modulation, namely subjective implicit, subjective explicit, objective implicit, and objective explicit. The co-occurrence between hedging and nominalization will be analyzed in each situation with example sentences from the selected abstracts. 
Situation (1): Subjective and explicit, the form of the sentence usually can be divided into mental clause + idea clause.

a. (Mental clause) This work suggests that + (Idea clause) there could be an expanded role for Cherenkov imaging as a tool to improve treatment protocols efficiently and as a potential verification tool for routine monitoring of unique patient treatments. $\left(\mathrm{H}-\mathrm{l}^{\wedge} \mathrm{N} 4\right)$

b. (Mental clause) Rietveld refinement of x-ray diffraction (XRD) data revealed that + (Idea clause) the single-phase, hexagonal wurtzite structure doesn't include any impurity phase. (H$\left.\mathrm{m}^{\wedge} \mathrm{N} 2\right)$

c. (Mental clause) Dose recalculations of clinical proton fields showed that + (Idea clause) metal artefacts cause range errors up to $6 \mathrm{~mm}$ distal to regions affected by $\mathrm{CT}$ artefacts. (H$\left.\mathrm{h}^{\wedge} \mathrm{N} 1\right)$

(Note: "H" in the bracket stands for "hedging", "l, $\mathrm{m}$ and h" refer to "low possibility value, medium possibility value and high possibility value"; "N" represents nominalization, and "N4" means that there four nominalization in the sentence. The analyzing results of sentences of different situations are presented in the following Table nine)

The above three sentences are all subjective explicit expressions in terms of modality. The subjectivity is reflected through the usage of verbs like "suggest, reveal, and show". Those "verbal hedging" in the mental clauses are employed to refine the degree of possibility of the following idea clauses, but due to the variance in the degree of possibility value of the verbs themselves, the degree of refinement on the possibility of the second idea clause also varies. For example, the use of "suggest" in sentence "a" exhibits a relatively lower possibility value compared with "reveal" in sentence "b" and "show" in sentence "c".

Based on the principle that the a harmonious balance should be reached between the ideational and the interpersonal meta-functions of language, when the possibility value of hedging is low, the credibility or authority of the sentence shall be enhanced by strengthening the ideational function to achieve the purpose of persuasion in academic writing. Nominalization, as the primary source of conceptual GM (Halliday \&Matthiessen, 2013), is used in the above example sentences to compensate for the low possibility value. For sentence "a", where the possibility value is the lowest among all three sentences, there are four nominalized expressions applied, namely "Cherenkov imaging", "treatment protocol", "verification ", and "patient treatments", to make up for the lower possibility of the "verbal hedge" : suggest. Accordingly, we can find the co-occurrence between nominalization and "verbal hedging" in the other two example sentences; and the number of nominalization in sentence " $b$ " is fewer than that in "a", i.e. "refinement" and "impurity", two nominalized expressions are used in sentence " $b$ " and only one nominalization- "recalculations" can be found in sentence "c", of which the verbal hedge "show" expresses the highest value of possibility.

Through the analysis of the above three example sentences that are subjective and explicit, it can be summarized that there not only exists co-occurrence of hedging and nominalization, but the number of applied nominalized expressions is also inversely correlated to the possibility value of hedging. What's left to be verified is whether the same inverse correlation can also be found in the other three situations of modal adjuncts.

Situation (2): Subjective and implicit modal structure, achieved through modal auxiliaries. $\mathrm{d}$. The presence of titanium hardware near the tumour may affect the dosimetric accuracy of 
proton therapy. $\left(\mathrm{H}-\mathrm{l}^{\wedge} \mathrm{N} 2\right)$

e. In this paper, we explore whether the encapsulation of infrared cyanine dyes within the core of lipid nanoparticles (LNPs) could improve their optical properties. $\left(\mathrm{H}-\mathrm{m}^{\wedge} \mathrm{N} 1\right)$

f. This would enable the development of MRI-Linac systems with no magnetic shielding around the Linac. $\left(\mathrm{H}-\mathrm{h}^{\wedge} \mathrm{N} 1\right)$

In subjective and implicit sentences, we can find the same co-occurrence pattern between hedging like modal auxiliaries and nominalization. When the possibility value is low, such as "may" in sentence "d", correspondingly, more nominalized expressions are adopted in the sentence. In sentence "e" and "f ", the possibility value of the modal auxiliary verbs "could" and "would" is relatively high, and fewer nominalized expressions are used, so as to achieve the balance between conceptual and interpersonal function. The same inverse correlation between the possibility value of hedging and the number of applied nominalized expressions can also be observed in the following Situation (3), when the sentences are objective and explicit.

Situation (3): The objective and explicit sentence, the modal structure was extracted into a projective clause.

g. In polycrystalline metals, it is taken for granted that the majority of grains are plastically deforming at the macroscopic yield stress. $\left(\mathrm{H}-\mathrm{h}^{\wedge} \mathrm{N} 1\right)$

h. However, it has been shown that fibres may also have negative effects on some properties of concrete, such as the workability, which get reduced with the addition of steel fibres. $\left(\mathrm{H}-\mathrm{m}^{\wedge} \mathrm{N} 2\right)$

i. It may be ascertained that a design change significantly reducing motor cooling would result in elevated bearing temperature, marginal lubrication, premature bearing failures, and reduced motor reliability. $\left(\mathrm{H}-1^{\wedge} \mathrm{N} 3\right)$

The same inverse correlation is also demonstrated in Situation (4), when the sentences are both objective and implicit. In addition, it can be seen from example sentence " $\mathrm{k}$ " and sentence "l" that, when the possibility value of the hedging is similar, the number of nominalized expressions applied in the sentence tends to be the same too. The difference in possibility value between "likely" and "possibly" is not peculiar, correspondingly, the number of nominalized expressions are the same for these two sentences.

Situation (4): Objective and implicit sentences, achieved through modal adverbs.

j.Managers have probably sanctioned the purchase of computer hardware and software but have not involved themselves with their use. ( $\left.\mathrm{H}-\mathrm{h}^{\wedge} \mathrm{N} 1\right)$

$\mathrm{k}$. Together, these are likely to drive an increase in the number of future clinical studies and the range of cancer sites in which US motion management is applied. (H-m^N2)

1. Facilities such as these will allow the engineer to possibly gain deeper systems understanding and through this to obtain greater diagnostic certainty. $\left(\mathrm{H}-\mathrm{l}^{\wedge} \mathrm{N} 2\right)$

After analyzing the co-occurrence between nominalization and hedging in the above four various situations, it can be deduced that there is a pattern for inverse correlation between the possibility value of hedging and the number of applied nominalized expressions in the sentence. Moreover, this inverse correlation is not influenced by the various forms of the hedging; the pattern has been verified in various situations with different forms of hedging, including "verbal hedging", "modal auxiliaries", "modal adverbs" and "projective clauses". The inverse correlation between the possibility value of hedging and the number of nominalized expressions used in sentenced of various situations is summarized in the following Table.9. 
Arab World English Journal (AWEJ) Volume 12. Number 1. March 2021

The Low Co-occurrence of Nominalization and Hedging

Liu

Table.9 Inverse correlation between possibility value of hedging and number of nominalization

\begin{tabular}{|c|c|c|c|c|c|c|c|c|}
\hline \multirow{2}{*}{$\begin{array}{l}\text { Possibility } \\
\text { value of } \\
\text { hedging }\end{array}$} & \multicolumn{8}{|c|}{ Number of Nominalization } \\
\hline & $\begin{array}{l}\text { Subjective } \\
\text { Explicit }\end{array}$ & $\&$ & $\begin{array}{l}\text { Subjective } \\
\text { Implicit }\end{array}$ & $\&$ & $\begin{array}{l}\text { Objective } \\
\text { Implicit }\end{array}$ & $\&$ & $\begin{array}{l}\text { Objective } \\
\text { Explicit }\end{array}$ & $\&$ \\
\hline H-high & 1 & & 1 & & 1 & & 1 & \\
\hline $\begin{array}{l}\text { M- } \\
\text { medium }\end{array}$ & 2 & & 1 & & 1 & & 2 & \\
\hline L-low & 4 & & 2 & & 2 & & 3 & \\
\hline
\end{tabular}

The Influence of Themacity on the Co-occurrence between Nominalization and Hedging of Scope

Guided by the balancing principle between ideational function and interpersonal function of language, the above section has investigated the co-occurrence between hedging and nominalization based on the categorization of modal adjuncts. The following part of the paper will investigate the relationship between hedging and nominalization depending on the position of the nominalization in message clauses, in other words, whether the location of nominalization in a message clause, in theme or rheme, could have different influence on the correlating pattern between hedging and nominalization. As stated in the introduction to functional grammar (Halliday \& Matthiessen, 2013), the discourse is usually considered unmarked when nominalization is loacted in the theme, and it belongs to marked discourses when it's positioned in the rheme, and the marked discourse normally has an enhanced ideational function. According to the balancing principle of language meta-functions, an intensified ideational function needs to be matched with a highlighted interpersonal function to maintain the balance, which is also claimed as related to the balance of semantic force by Talmy (1988).

When nominalization is in the theme of the clause, it is unmarked and the ideational function is not intentionally strengthened. Thus it is not particularly necessary to use hedging with high generality value, or relatively weak scope-refinement, to reach a broader interpersonal influence. For example, in the following sentence "m", the primary process "addition"(nominalization) is located in the theme of the sentence, which is considered as unmarked, and it can be seen that the hedge used in the rheme is "particularly", which ranks low in the generality value scale.

Sentence $\mathrm{m}$.

Theme: The addition of fibres in high-performance concrete

Rheme: has been proven to improve the mechanical properties of concrete, particularly the TS, flexural strength, and ductility performance.

Sentence $\mathrm{m}$. shows that when nominalization is located in theme, it's more likely for hedging with low generality value to appear in the rheme; whether there is difference when nominalization is located in the rhemes will be demonstrated through the analysis of following example sentences. When nominalization is in the rheme, it is marked and the ideational function is strengthened. The balancing principle of language meta-functions would require a hedge of higher generality value to magnify the interpersonal influence. And the following Sentence n. and o. further proved this argument. In the following sentences "n" and "o", primary nominalization such as "modifications", "registration" and "fusion" all appear in the rhemes, which is considered as marked and would enhance ideational function. Correspondingly, scope 
hedging with higher generality value are used, such as "some" and "most", enhancing the interpersonal function to counterbalance the amplified ideational function, so to achieve coordinated balance between meta-functions of language.

\section{Sentence n.}

\section{Theme: We present}

Rheme:some of the reported surface and bulk modifications of the scaffolds, which positively affected cell performance.

Sentence o.

Theme:Most treatment planning systems

Rheme:support some form of image registration and fusion to allow the use of multimodality.

In the following Sentence "q", two parallel clauses are connected by "and". The first clause has nominalization within the theme, and the only scope hedge found in the clause is "particularly", which has low generality value. While in the second clause, nominalization is embedded in the rheme, then the scope hedge with high generality value- "some" is applied. Sentence "q". is also in consistent with the hypothesized pattern for the co-occurrence between hedging and nominalization: when nominalization is located in the theme, there's a higher possibility that hedging with low generality value will appear in the clause; when nominalization is the rheme, then hedging with high generality value are more likely to be found in the clause. The deep-rooted reason for this co-occurrence pattern also dates back to the balancing principle between conceptual and interpersonal functions proposed in SFL.

\section{Sentence q.}

Theme 1:The addition of fibres, particularly steel fibres,

Rheme1:due to their conductivity leads to a significant reduction in the electrical resistivity of the concrete.

Theme2:and it

Rheme2:also results in some reduction in the chloride penetration resistance of the concrete

\section{Conclusion and Implications}

This article has applied both quantitative and qualitative methods in verifying the hypothesis that nominalization and hedging tend to co-occur in scientific papers, abstracts in particular, both at the textual level and clausal level. Based on the min-corpus made of 60 academic abstracts of leading international journals written by native English speakers, we found that the number of sentences with nominalization is positively correlated to the number of sentences containing hedging through a linear regression analysis. Besides, the BNC corpus search has further proven that the frequency of the co-occurrence between nominalization and hedging at the clausal level in scientific papers is significantly higher than that of non-academic texts. After the corpusbased statistical analysis, a tentative reason analysis of their co-occurrence at clausal level was carried out under the coordinated balance principle of language meta-functions in SFL. The example sentences were analyzed in terms of negotiability and thematicity, and it is revealed that the number of nominalization in clauses is inversely correlated to the possibility value of the hedging; in addition, the position of nominalization in a message clause (in theme or rheme) has impact on the generality value of hedging, theme-oriented nominalization usually indicates hedging with lower generality value, and rheme-oriented nominalization tends to co-occur with hedging of high generality value. 
Language is considered as an evolving integrated system made of conceptual, interpersonal and textual meta-functions in SFL. In terms of academic discourse, which is featured by authority and information density, it is necessary to appropriately highlight interpersonal function to dilute the side-effect of enhanced ideational functions resulted from the increased percentage of nominalization- the key resource to reach and maintain the academic authoritarian characteristics. The approaches to amplify interpersonal functions include the use of degree hedging and scope hedge to increase negotiability, balance thematicity, and finally achieve coordinated balance between language meta-functions. The quantitative and qualitative analysis of the co-occurrence between nominalization and hedging in scientific papers could lend supporting evidence to these arguments.

Besides, by trying to explain the ideational and interpersonal functions of lexicongrammatical structure, by highlighting the interactions between authors of the scientific papers and the readers through zooming in on the meaning production and interpretation procedures, this article has brought some inspirations to the traditional English grammar teaching in EAP teaching in China. The analysis of the linguistic meta-functions and the disclosure of the interpersonal meanings of the co-occurrence between nominalization and hedging can give students a deeper understanding of the functions and interactions between Grammatical Metaphors and the author's deep-lying communicative purpose underlying the superficial form, providing a cognitive-pragmatic angle to interpret the embedded interactions between scientific paper writers and their potential readers. In this way, it's hoped that Chinese postgraduates who are under the pressure of international publications can be released from the cognitive load in memorizing all the fixed sentence patterns in academic discourse, and can really improve both their metaphorical competence and the capability in producing academically valued texts, which is the key in joining the international academic community of certain professional domain. Furthermore, by looking into the relationship between various common GMs in academic discourse, the current study provides a new route to deepen the integration of SFL theory in EFL instruction in China. However, this article's implication in pedagogy is limited by the size of the corpus, the number of analyzed example sentences, and it is merely devoted to a tentative reason analysis of the possible co-occurrence between nominalization and hedging in abstracts within the theoretical framework of SFL, more profound practical analyses of various patterns in academic writing guided by theories in cognitive linguistics, sociolinguistics, as well as pragmatics are needed.

\section{Acknowledgment:}

This paper is funded by the project "International Communication English Curriculum Design Based on Critical Thinking and Culture Studies"(5645006) of NUAA

\section{About the Author:}

Dr. Xiao Liu received her Ph.D. in linguistics from Lomonosov Moscow State University. She has been teaching at the College of Foreign Languages in Nanjing University of Aeronautics and Astronautics since 2016. Her primary research interests lie in metaphor, discourse analysis, and English for Academic Purposes. She was funded by the university to investigate EAP teaching for postgraduates. ORCID iD:0000-0001-6365-1191 
Arab World English Journal (AWEJ) Volume 12. Number 1. March 2021

The Low Co-occurrence of Nominalization and Hedging

Liu

\section{References}

Biber, D. (2006). University language: A corpus-based study of spoken and written registers. Philadelphia/Amsterdam: John Benjamins.

Brown, P., \& Levinson, S. (1978). Universals in Language Usage: Politeness Phenomena. In E. Goody (Ed.), Questions and Politeness: Strategies in Social Interaction(pp. 56-311). Cambridge: Cambridge University Press.

Cai, L.Q., \& Dai W. D.(2002). Research on the possibility of precise discourse information of restricted language. Foreign Languages and Foreign Language Teaching, 08, 1-6.

Campbell, K. P., \& Yong, Z. (1993). The Dilemma of English Language Instruction in the People's Republic of China. Tesol Journal, 2(4), 4-6.

Charles, M. (2003). "This mystery.": A corpus-based study of the use of nouns to construct stance in theses from two contrasting disciplines. Journal of English for Academic Purposes, 2(3), 313-326

Chen, H. Q., \& Xiong, W.Q. (2010). Investigation and research on the nominalization of English abstracts of Chinese master degree thesis. Journal of Dalian University of Technology (Social Science Edition), 31(4), 106-110.

Chen, H., \& Wen, Q. F. (2020). Nominalization of academic English writing based on "output oriented approach": a case study of facilitation teaching. Research frontier of Foreign Language Education, (01), 15-23.

Fan W.F. (1999). Nominalized Text Cohesion Function. Foreign Language Research, (01), 9-12.

Flowerdew, J. (1997). The discourse of colonial withdrawal: a case study in the creation of mythic discourse. Discourse \& Society, 8(4), 453-477.

Halliday, M. A., \& Hasan, R. (1985). Language, text and context. Victoria: Derkin University.

Halliday, M. A. K., \& Matthiessen, C. M. (2013). Halliday's introduction to functional grammar. London:Routledge.

Halliday, M. A. K., \& Matthiessen, C. (2006). Construing experience through meaning: A language-based approach to cognition. Computational Linguistics, 27(1), 140-142

Huang, G. W. (2002). Hallidayan linguistics in China. World Englishes, 21(2), 281-290. https://doi.org/10.1111/1467-971X.00248

$\mathrm{Hu}, \mathrm{Z}$. L., \& Fang, Y. (Eds.). (1997). Advances in functional linguistics in China. Beijing: Tsinghua University Press.

Hyland, K. (1998). Hedging in Scientific Research Articles. Amsterdam/Philadelphia: John Benjamins Publishing Company.

Hyland, K. (2004a). Disciplinary discourses: Social interactions in academic writing. Ann Arbor, MI: University of Michigan Press.

Hyland, K. (2005). Stance and engagement: A model of interaction in academic discourse. Discourse Studies, (2), 173-192.

Hyland, K. (2004). Genre and second language writing. Ann Arbor, MI: University of Michigan Press

Jiang, P. (2013). Domestic fuzzy language research: current situation and goals. Foreign Languages (Journal of Shanghai International Studies University), 36(05), 43-49.

Jiang, F. (2016). Stance construction and interpersonal interaction of shell nouns. Contemporary Foreign Languages, 39(04), 470-482.

Lam, A. (2002). English in education in China: Policy changes and learners' experiences. World Englishes, 21(2), 245-256. https://doi.org/10.1111/1467-971X.00245

Lakoff, G. (1975). Hedges: A study in meaning criteria and the logic of fuzzy concepts. In 
Contemporary research in philosophical logic and linguistic semantics (pp. 221271). Springer, Dordrecht.

Lemke, J. L. (1998). Multimedia demands of the scientific curriculum. Linguistics and Education, 10 (3): 247-272.

Liardét, C. L. (2013). An exploration of Chinese EFL learner's deployment of grammatical metaphor: Learning to make academically valued meanings. Journal of Second Language Writing, 22(2), 161-178.

Liardét, C. L., \& Black, S. (2020). Trump vs. Trudeau: Exploring the power of grammatical metaphor for academic communication. Journal of English for Academic Purposes, $45,1-14$.

Liu Y. F., \& Chen Z.L. (2019). An Empirical Study on the nominalization of English titles of Chinese and foreign master's degree theses. Foreign language teaching, (05), 18-23.

Li, W., \& Guo J.H. (2020). The ideational GM competence of Chinese advanced English learners: a corpus-based study of $\mathrm{Ph} \mathrm{D}$ theses. Foreign Language Teaching: Theories and Practice, (01), 50-58.

Luo L. Sh. (2007). A Study and Analysis of English Nominal Errors in Learners' Interlanguage. Foreign Language Teaching, (01), 56-59.

Martin, J. R. (1992). English Text: System and Structure. Amsterdam: Benjamins. http://dx.doi.org/10.1075/z.59

Park, H. (2019). Grammatical Metaphor in Academic Writing: Focusing on Nominalization and Verbalization. The Journal of Linguistics Science, 89, 65-86.

Prasithrathsint, A. (2014). Nominalization as a marker of detachment and objectivity in Thai academic writing. MANUSYA: Journal of Humanities, 17(3), 1-10. https://doi.org/10.1163/26659077-01703001

Prince, E., Frader, J., \& Bosk, C. (1982). On hedging in physician-physiciandiscourse. In R. J. di Pietro (Ed.), Linguistics and the professions (pp. 83-97). Hillsdale, NJ: Ablex.

Ryshina-Pankova, M. (2015). A meaning-based approach to the study of complexity in L2 writing: The case of grammatical metaphor. Journal of Second Language Writing, 29, 51-63. https://doi.org/10.1016/j.jslw.2015.06.005

Schleppegrell, M. J. (2005). Technical writing in a second language: The role of grammatical metaphor. In L. J. Ravelli, \& R. A. Ellis (Eds.), Analysing academic writing: Contextualized frameworks (pp. 172-189). Cambridge: A\&C Black

Swales, J. (1990). Genre analysis: English in academic and research settings. London: Cambridge University Press.

Sun Yanmei \& Shao Xinguang. (2011). Grammatical metaphor and English reading. Journal of Southwest University for Nationalities (Humanities and Social Science) (07), 189191.

Talmy, L. (1988). Force dynamics in language and cognition. Cognitive science, 12(1), 49-100.

Tang, G. L.(2014). The use of nominalization in abstracts and meta-function analysis. Journal of Changchun Normal University, 33(09), 73-77.

Tan L. H. (2011). A Corpus-based Study on Metaphoric Application of Nominalization in Scientific Discourses:A Case Study of Chinese EFL Learners' and English Native Speakers' Abstract of Science and Engineering Master's Thesis. Journal of Hunan University of Science and Technology (Social Science Edition), 14(04), 130-134.

Wang J.G \& Sun F.L. (2018). A study on the characteristics of mild hedges in academic oral English. Foreign Language Teaching (03), 66-70, doi:10.16362/j.cnki.cn61- 
1023/h.2018.03.014.

Xu, C.X. (2006). Pragmatic Functions of English hedging. Foreign Language Teaching, (04), 3739.

Xu, H.L. (2011). Use of Authorial Stance Markers in Research Discourse by Chinese Advanced EFL Learners: A Corpus-based Contrastive Study. Foreign Language Teaching, 32(06), 44-48.

Yang, Y. N. (2011). Grammatical metaphor in Chinese: A corpus based study. Functions of Language, 18(1), 1-28.

Ying G. L., \& Zhou, H. (2009). A Study on the Relevance of Pragmatic Functions of hedging and Politeness Principles. Chinese Foreign Languages, 6(02), 43-47.

Yoon, C. (2018). Nominalization in Korean EFL Learners' Argumentative Writing: A Comparative Study of Distribution and Use. The New Studies of English Language \& Literature, 69, 249-274.

Zhang Liping(2016). A Study of Metaphoric Function and Translation of Nominalization in Policing English Discourse. Technology Enhanced Foreign Language Education (01), 73-78.

Zhou, H., \& Liu, Y. B. (2017). The Use of GMs and Textual Functions in Abstracts of English Degree Thesis. Modern Foreign Languages, 40(04), 484-494.

Zhu, K., \& Xia, X.R. (2011). A Study on the Correlation between hedging and Written Communicative Ability. Foreign Language Teaching, 32(05), 31-34

Zhu yeqiu \& Chen Xinren. (2015). Boundedness construal and countability acquisition:A cognitive account of English learners' misuse of noun countability. Foreign Language Learning Theory and Practice (02), 1-6.

Zhu Y. Sh. (1994). Grammatical metaphor in English. Foreign languages (Journal of Shanghai Institute of foreign languages) (01):8-13.

Zhu Y. Sh. (2006). Nominalization, verbalization and GMs. Foreign Language Teaching and Research, (02), 83-90.

Zhu Y. Sh., \& Yan Sh.Q. (2000). Motivation and Contribution of Grammatical Metaphor Theory. Foreign Language Teaching and Research (02), 95-102.

Zhong L.F., \& Chen X.H. (2015). Research on the Output Ability of Academic English Metaphors. Modern Foreign Languages, 38(03), 386-395. 